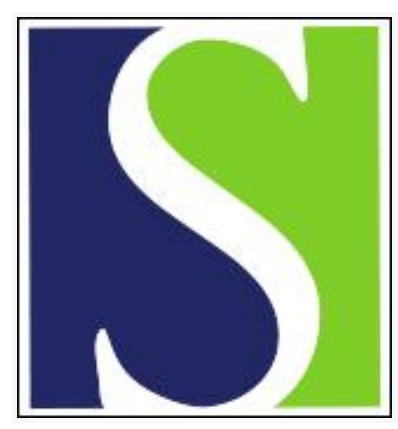

Scand J Work Environ Health 1997;23(4):289-298

https://doi.org/10.5271/sjweh.222

Issue date: Aug 1997

Toluene-induced hearing loss among rotogravure printing workers

by Morata TC, Fiorini AC, Fischer FM, Colacioppo S, Wallingford KM, Krieg EF, Dunn DE, Gozzoli L, Padrão MA, Cesar CLG

The following article refers to this text: 2001;27(5):335-342

Key terms: biological monitoring; ethanol; ethyl acetate; hippuric acid; interaction; noise

This article in PubMed: www.ncbi.nlm.nih.gov/pubmed/9322820

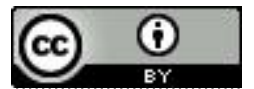




\title{
Toluene-induced hearing loss among rotogravure printing workers
}

\author{
by Thais C Morata, PhD, ${ }^{1,2}$ Ana Claudia Fiorini, MSc, ${ }^{3,2}$ Frida Marina Fischer, PhD, ${ }^{2}$ \\ Sergio Colacioppo, PhD, ${ }^{2}$ Kenneth M Wallingford, MSC, ${ }^{4}$ Edward F Krieg, PhD, ${ }^{1}$ \\ Derek E Dunn, PhD, ${ }^{1}$ Luciane Gozzoli, BSc, ${ }^{3}$ Maria Aparecida Padrão, BSc, ${ }^{2}$ \\ Chester Luiz G Cesar, PhD
}

\begin{abstract}
Morata TC, Fiorini AC, Fischer FM, Colacioppo S, Wallingford KM, Krieg EF, Dunn DE, Gozzoli L, Padrão MA, Cesar CLG. Toluene-induced hearing loss among rotogravure printing workers. Scand J Work Environ Health 1997;23(4):289-98.
\end{abstract}

\begin{abstract}
Objectives This study explored the effects of occupational exposure to solvents and noise on the hearing of rotogravure printing workers from São Paulo, Brazil.

Methods The study group comprised 124 workers exposed to various levels of noise and an organic solvent mixture of toluene, ethyl acetate, and ethanol. Data on work history, psychosocial aspects of the job, medical history, present health, stress, occupational and nonoccupational exposures to noise or chemicals, and life-style factors were collected through an interview. The participants underwent pure-tone audiometry and immittance audiometry testing. Their exposures to noise and solvents were assessed.

Results Forty-nine percent of the workers had hearing loss. From the numerous variables that were analyzed for their contribution to the development of hearing loss (age, tenure, noise dose, solvent concentrations in air, biological marker for toluene, job category, work and medical history items, smoking, alcohol consumption, work perception scores, nonoccupational exposures), age and hippuric acid (the biologic marker for toluene in urine) were the only variables that met the significance level criterion in the final multiple logistic regression model. The odds ratio estimates for hearing loss were 1.07 times greater for each increment of 1 year of age [95\% confidence interval $(95 \% \mathrm{CI}) 1.03-1.11]$ and 1.76 times greater for each gram of hippuric acid per gram of creatinine (95\% CI $1.00-2.98)$.

Conclusions The findings suggest that exposure to toluene has a toxic effect on the auditory system. Further research is needed on the mechanisms underlying the effects of toluene and on the adequacy of current recommended exposure limits.
\end{abstract}

Key terms biological monitoring, ethanol, ethyl acetate, hippuric acid, interaction, noise.

In recent years, increasing attention has been given to a holistic approach to studying the workplace as a combination of physical, chemical, biological, and organizational factors that impact workers' health and welfare. This approach includes initiatives to investigate the combined effects of occupational exposure to noise and other factors on hearing. In particular, the potential interaction between noise and chemicals poses a new challenge to investigators and hearing conservationists.
Animal experiments shed light on the ototoxicity of industrial chemicals like metals, asphyxiants, and organic solvents $(1-6)$. Many chemicals have been shown to be ototoxic, and, in the case of solvents and asphyxiants, some will have a synergistic effect when presented in conjunction with noise $(7-9)$. When rats were exposed to combinations of solvents, different patterns of interaction, from antagonism to potentiation, were reported. [For a recent review, see reference 10.]

1 National Institute for Occupational Safety and Health, Division of Biomedical and Behavioral Science, Cincinnati, Ohio, United States.

2 Department of Environmental Health, School of Public Health, University of São Paulo, São Paulo, Brazil.

3 Division of Education and Rehabilitation of Communication Disorders, Pontifical Catholic University of São Paulo, São Paulo, Brazil.

4 National Institute for Occupational Safety and Health, Division of Surveillance, Hazard Evaluations, and Field Studies, Cincinnati, Ohio, United States.

5 Department of Epidemiology, School of Public Health, University of São Paulo, São Paulo, SP, Brazil.

Reprint requests to: Dr Thais C Morata, Arbmed/E National Institute for Working Life, S 17184 Solna, Sweden. 
In the past decade, evidence from studies on the effects of occupational exposure to chemicals and noise has also become available. In a 20-year longitudinal study on the hearing sensitivity of 319 Swedish workers (11), $23 \%$ of the workers from the chemical department exhibited pronounced hearing loss from exposure to lower noise levels $(80-90 \mathrm{dBA})$ than the $5 \%$ to $8 \%$ of workers from nonchemical environments with exposure to higher noise levels (95-100 dBA). The increased prevalence of high-frequency hearing loss has been reported after solvent exposure in the presence of noise levels below recommended limit values (12-15). It has also been suggested that exposure to solvents interacts with noise so that the combined exposures yield an increased prevalence of high-frequency hearing loss (1517). In a cross-sectional study that investigated the hearing sensitivity of workers from rotogravure printing and paint manufacturing industries, the adjusted relative risk was 4 times greater for the noise-exposed group than for an unexposed reference group, 11 times greater for the group exposed simultaneously to noise and toluene, and 5 times greater for the group exposed only to a mixture of organic solvents (15). Moreover, clinical studies which performed a comprehensive audiologic battery showed a central component for the observed auditory disorders $(18-21)$. This observation indicates that auditory retrocochlear disorders due to solvent exposure exist and that they could represent a more debilitating impairment than the one caused by noise.

As part of the University of São Paulo School of Public Health study of the effects of environmental and organizational stressors, reported elsewhere (22), we used pure-tone audiometry to evaluate the occurrence of hearing disorders in workers exposed to various levels of noise and solvents at a printing facility. Moreover, acoustic reflex measurements were performed with the objective of obtaining information concerning the anatomical location of the observed hearing disorders.

\section{Subjects and methods}

The design of the University of São Paulo School of Public Health study was cross-sectional and was meant to assess the combined effects of environmental and work

Table 1. Characterization of the study population $(N=124)$.

\begin{tabular}{lrrr}
\hline Variable & \multicolumn{3}{c}{ Years } \\
\cline { 2 - 4 } & Mean & SD & Range \\
\hline Age & 33.8 & 8.5 & $21-58$ \\
Tenure & 7.7 & 6.1 & $1-25$ \\
Noise exposure & 7.7 & 6.0 & $0-25$ \\
Solvent exposure & 6.5 & 6.0 & $0-25$ \\
Previous noise exposure & 2.2 & 4.3 & $0-26$ \\
Previous solvent exposure & 1.8 & 4.2 & $0-22$ \\
\hline
\end{tabular}

organization stressors on various health outcomes and the well-being of workers in the rotogravure printing industry (22). The subjects were male workers employed for a minimum of 1 year. Data were collected through an interview based on a questionnaire comprising approximately 400 questions on psychosocial aspects of work, work history, work organization, medical history, present health, stress, occupational and nonoccupational exposure, and life-style factors. (See a list summarizing the contents of the questionnaire in the appendix.) The interview protocol included questions concerning demographic data, health information that focused on events that could be related to hearing status, and nonoccupational noise exposure data. The self-reported medical history included data on diabetes, prior ear surgery, head injury, high fever, measles, high blood pressure, mumps, ear infections, history of hearing loss in the family, use of ototoxic medication, and tinnitus. Medical history items like diabetes and high blood pressure were reported as positive if the employee had received or was receiving treatment for the listed condition. For the present analysis, results of audiological tests and measurements of individual exposures to noise and solvents, including biological monitoring, were added to each questionnaire after each worker was interviewed.

\section{Study population}

All of the workers from the departments of rotogravure printing, paint preparation, engraving, lamination, color proofing and cylinder preparation who met the eligibility criteria were invited and accepted to participate in the study $(\mathrm{N}=124)$. These departments were selected because of their exposures to noise or solvents. The mean tenure of the group at the studied company was 7 years, ranging from 1 to 25 years. The mean age of the group was 33.8 years, ranging from 21 to 58 years of age. During the data collection, the participants worked in 8 -hour shifts (0600 to 1400,1400 to 2200 , and 2200 to 0600), which rotated monthly. Twelve of the participants worked on a fixed shift from 0600 to 1400 . On alternate weeks, the participants worked on Saturdays, completing 48 hours of work in a week.

The characteristics of the study population regarding their tenure, current and previous exposure to the studied agents, and age are presented in table 1. Table 1 reveals that the study group comprised a fairly young sample of employees, with relatively short tenure and previous exposures to noise or solvents.

\section{Solvent exposure assessment}

In the printing company studied, the participants were exposed to solvent mixtures composed mainly of toluene, ethyl alcohol (ethanol), and ethyl acetate. Although different proportions of each of these 3 solvents were used in the printing of different products, these solvents 
were always predominant (comprised $90 \%$ of the mixture). Other components found in small proportions included methyl ethyl ketone, isopropyl alcohol, and cellosolve. To determine the level of exposure to these predominant solvents, a personal, full-shift, time-weighted average (TWA) exposure evaluation was conducted for all the subjects for toluene, ethanol, and ethyl acetate according to methods 1501,1400 , and 1457 , respectively, of the National Institute for Occupational Safety and Health (NIOSH) (23). For this purpose, air from the breathing zone of each subject was drawn at a specified flow rate, for a known duration of time, through a glass adsorption tube using a precalibrated personal sampling pump. For the evaluation of toluene and ethyl acetate exposure, $100 / 50 \mathrm{mg}$ (primary/back-up) activated charcoal tubes were used. Preliminary ethanol exposure assessment was conducted using 400/200 mg activated charcoal tubes. For the investigation, however, ethanol exposure monitoring was conducted using $100 \mathrm{mg}$ and $50 \mathrm{mg}$ anasorb tubes in sequence to prevent potential interference from high relative humidity during the sampling. After the exposure monitoring was completed, the adsorption tube samples were securely sealed by the plastic caps provided, stored on ice, and sent to NIOSH for analysis. The air samples were analyzed for toluene, ethanol, and ethyl acetate by gas chromatography using NIOSH methods 1501,1400 , and 1457, respectively (23).

The concentration of the mixture in the air relative to their respective exposure limits was calculated according to the formula of the American Conference of Governmental Industrial Hygienists (ACGIH) for mixtures, the Brazilian exposure limits for ethyl acetate and ethanol (1090 $\mathrm{mg} / \mathrm{m}^{3}$ and $1480 \mathrm{mg} / \mathrm{m}^{3}$, respectively), and the ACGIH threshold limit value (TLV) for toluene $\left(188 \mathrm{mg} / \mathrm{m}^{3}\right)(24,25)$. The exposure index (EI) for each of the solvents was calculated by dividing the observed atmospheric concentration $(\mathrm{C})$ by the corresponding exposure limit (EL). If the results of the division was greater than unity, the exposure limit was considered to be exceeded (24). The fractions for the 3 solvents were summed in order to obtain the exposure index for the mixture (C1/EL1 + C2/EL2 + C3/EL3), and exposure to the mixture was considered to be exceeded when the sum was greater than unity.

One hundred and nine solvent-exposed workers had their total toluene exposure assessed by the biological monitoring of hippuric acid and creatinine in their urine. The urine samples were collected from these workers immediately after the end of the workday and analyzed by gas chromatography according the method described by Carvalho et al (26). The levels of hippuric acid were normalized to the creatinine levels prior to use in the statistical analyses and reporting.

The levels of ethanol in air ranged from below the limit of detection of 0.25 to $1240 \mathrm{mg} / \mathrm{m}^{3}$, and its expo- sure index never exceeded unity. The ethyl acetate concentrations in air ranged from 1.1 to $2635 \mathrm{mg} / \mathrm{m}^{3}$. The highest ethyl acetate concentrations were observed in the rotogravure printing and lamination departments, for which the exposure indices were greater than 1 for some job categories. The levels of toluene in the air ranged from 0.14 to $919 \mathrm{mg} / \mathrm{m}^{3}$. The highest toluene levels were observed in the engraving and rotogravure printing departments, the only areas in which the exposure index exceeded unity. Often, when exposure indices were calculated for the mixture of the 3 solvents, the toluene levels caused the resulting concentrations to be greater than 1 . The results of the biological monitoring of toluene indicated that $8 \%$ of the workers had levels of urinary hippuric acid that exceeded $2.5 \mathrm{~g} / \mathrm{g}$ creatinine, the ACGIH recommended biological exposure index (BEI) (24). Table 2 presents the distribution of the workers by

Table 2. Distribution of the study population by the duration of their exposure to solvents, by exposure levels, expressed in environmental exposure indices and the biological exposure index (BEI).

\begin{tabular}{|c|c|c|c|c|c|}
\hline & \multicolumn{5}{|c|}{ Number of workers by exposure timea } \\
\hline & $\begin{array}{l}1-3 \\
\text { years }\end{array}$ & $\begin{array}{l}4-6 \\
\text { years }\end{array}$ & $\begin{array}{l}7-16 \\
\text { years }\end{array}$ & $\begin{array}{c}17-25 \\
\text { years }\end{array}$ & Total \\
\hline \multicolumn{6}{|l|}{ Exposure index } \\
\hline \multicolumn{6}{|l|}{ Ethanol } \\
\hline $\begin{array}{l}\leq 0.50 \\
0.51-0.60\end{array}$ & $\begin{array}{r}22 \\
1\end{array}$ & $\begin{array}{r}53 \\
2\end{array}$ & 31 & 15 & $\begin{array}{r}121 \\
3\end{array}$ \\
\hline \multicolumn{6}{|l|}{ Ethyl acetate } \\
\hline $\begin{array}{l}\leq 0.50 \\
0.51-0.80 \\
1.00-1.20\end{array}$ & $\begin{array}{r}21 \\
2 \\
-\end{array}$ & $\begin{array}{r}49 \\
5 \\
1\end{array}$ & $\begin{array}{r}22 \\
4 \\
5\end{array}$ & $\begin{array}{r}12 \\
2 \\
1\end{array}$ & $\begin{array}{r}104 \\
13 \\
7\end{array}$ \\
\hline \multicolumn{6}{|l|}{ Toluene } \\
\hline $\begin{array}{l}\leq 0.50 \\
0.51-0.99 \\
1.00-1.50 \\
2.00-2.79 \\
2.83-3.35\end{array}$ & $\begin{array}{r}13 \\
4 \\
2 \\
3 \\
1\end{array}$ & $\begin{array}{r}43 \\
6 \\
1 \\
2 \\
4\end{array}$ & $\begin{array}{r}22 \\
7 \\
-1\end{array}$ & $\begin{array}{r}12 \\
2 \\
-1 \\
-\end{array}$ & $\begin{array}{r}90 \\
19 \\
3 \\
6 \\
6\end{array}$ \\
\hline \multicolumn{6}{|l|}{ Solvent mixture } \\
\hline $\begin{array}{l}\leq 0.50 \\
0.65-0.99 \\
1.00-1.50 \\
1.54-3.38\end{array}$ & $\begin{array}{r}17 \\
5 \\
1 \\
9\end{array}$ & $\begin{array}{r}30 \\
4 \\
5 \\
10\end{array}$ & $\begin{array}{r}20 \\
5 \\
-7\end{array}$ & $\begin{array}{r}8 \\
1 \\
2 \\
-\end{array}$ & $\begin{array}{r}75 \\
15 \\
8 \\
26\end{array}$ \\
\hline \multicolumn{6}{|c|}{ Biological exposure index } \\
\hline \multicolumn{6}{|c|}{$\begin{array}{l}\text { Urinary hippuric acidc } \\
\text { (g/g creatinine) }\end{array}$} \\
\hline $\begin{array}{l}<0.50 \\
0.5-<1.0 \\
1.0-<1.5 \\
1.5-<2.5 \\
2.5-<3.0 \\
3.0-<4.2 \\
4.2-<5.5\end{array}$ & $\begin{array}{l}8 \\
2 \\
2 \\
3 \\
1 \\
2\end{array}$ & $\begin{array}{r}25 \\
9 \\
3 \\
5 \\
1 \\
5 \\
-\end{array}$ & $\begin{array}{l}16 \\
10 \\
2 \\
- \\
-\end{array}$ & $\begin{array}{r}8 \\
4 \\
1 \\
2 \\
- \\
-\end{array}$ & $\begin{array}{r}57 \\
25 \\
6 \\
12 \\
1 \\
6 \\
2\end{array}$ \\
\hline
\end{tabular}

a Numbers in italics indicate workers overexposed to the solvent in

- Euestion. in the ranges of the exposure data indicate that no observations were made between the reported ranges.

- Hippuric acid samples were used as the biological exposure determinant for toluene. Biological monitoring of toluene was performed for 109 workers. 
the duration of their solvent exposure in years and exposure to each of the solvents expressed as their environmental exposure indices and as the BEI for toluene. Exposure index values above 1 and the urinary hippuric acid values above $2.5 \mathrm{~g} / \mathrm{g}$ creatinine indicate overexposure to the solvent. The results of the toluene measurements in air and in urine were found to be correlated $(r=0.60, P<0.0001)$.

\section{Noise exposure assessment}

The sound pressure measurements conducted during our investigation, using a sound pressure level meter model 2231 from Bruel \& Kjær, were in agreement with the company's historical records. These measurements revealed continuous noise levels in the range of 71 to 93 $\mathrm{dB}(\mathrm{A})$. Noise-level maps and job descriptions were used to plan the noise dosimetry for each subject. Those who worked at the same job during their entire shift wore the noise dosimeter for 3 hours, and the results were used to estimate their 8-hour noise dose. Workers who performed tasks in different locations wore the noise dosimeter during their full shift. Noise dosimetry, conducted with Bruel \& Kjær dosimeters (model 4436), indicated doses that ranged from $43 \%$ to $300 \%$. The Brazilian (and NIOSH) recommended limit of $85 \mathrm{dBA}$ and the $5 \mathrm{~dB}$ exchange rate were used in these evaluations. The exchange rate describes a relation between time of maximum permissible exposure and sound level. In this case, they varied in an inversely proportional manner so that, as the sound level increased, the time of maximum permissible exposures decreased, and vice versa.

Table 3. Distribution of the exposure population by the timeweighted average of their noise levels and their mean duration of noise exposure.

\begin{tabular}{lccc}
\hline $\begin{array}{l}\text { Time-weighted } \\
\text { average noise } \\
\text { levels }\end{array}$ & \multicolumn{2}{c}{ Workers } & $\begin{array}{c}\text { Mean duration of } \\
\text { noise exposure } \\
\text { (years) }\end{array}$ \\
\cline { 2 - 4 } & $\mathrm{N}$ & $\%$ & 10.1 \\
$\leq 80 \mathrm{dBA}$ & 20 & 16.1 & 9.9 \\
$81-85 \mathrm{dBA}$ & 30 & 24.2 & 6.1 \\
$86-90 \mathrm{dBA}$ & 52 & 42.0 & 7.3 \\
$\geq 91 \mathrm{dBA}$ & 22 & 17.7 & \\
\hline
\end{tabular}

Table 4. Range of the noise levels observed in the studied departments.

\begin{tabular}{lcc}
\hline Department & $\begin{array}{c}\text { Number of } \\
\text { workers }\end{array}$ & $\begin{array}{c}\text { Range of the noise } \\
\text { levels (in dBA) }\end{array}$ \\
\hline Printing (press 1) & 10 & $89.2-92.7$ \\
Printing (press 2) & 9 & $89.4-90.1$ \\
Printing (press 3) & 11 & $80.7-85.1$ \\
Paint preparation & 20 & $90.1-92.8$ \\
Engraving & 14 & $70.5-72.7$ \\
Cylinder preparation & 24 & $83.2-84.5$ \\
Lamination (laminator 1) & 14 & $89.4-90.9$ \\
Lamination (laminator 2) & 16 & $86.9-87.5$ \\
Color Proofing & 6 & $87.1-87.8$ \\
\hline
\end{tabular}

Table 3 shows the number and percentage of workers, divided by their mean duration of noise exposure, and by the noise time-weighted averages (TWA) that corresponded to their job categories.

Tables 2 and 3 indicate that the workers with longer tenure were the ones exposed to lower noise and solvent levels. Table 4 summarizes the noise levels observed in each of the studied departments and the number of workers in each department.

\section{Testing procedures}

To assess the workers' hearing status, otoscopy, puretone audiometry, and immittance audiometry were performed. These tests were administered by audiologists, under the supervision of an audiology instructor. Otoscopy was performed to screen for conditions that would exclude the person from the study (ie, external otitis or perforated tympanic membrane).

\section{Pure-tone audiometry}

Pure-tone audiometry was performed for all the subjects at the frequencies of $0.5,1,2,3,4,6$, and $8 \mathrm{kHz}$. Testing was preceded by a period of at least 14 hours without exposure to occupational noise. Bone conduction testing was performed for the affected frequencies in the range of 0.5 to $4 \mathrm{kHz}$. The subjects were tested in a soundinsulated chamber which met the requirements of the American standard ANSI S 3.1.- 1991 for audiometric testing environments (27). The Maico MA-41 audiometer was calibrated following the ISO R389-1964 norm (28) prior to the data collection. Daily biological calibration checks were also performed immediately before the subjects were tested.

The high-frequency hearing losses were classified by severity with the use of the clinical criteria detailed elsewhere (15). Audiograms were classified as normal if no single threshold exceeded $25 \mathrm{~dB}$. The thresholds in the frequency ranges 0.5 to $2 \mathrm{kHz}$ were averaged. The bilateral threshold average of the most affected frequency in the 3 to $8 \mathrm{kHz}$ frequency range was considered in assigning a classification to the audiograms. A nonoccupational category was included to account for the hearing losses that could not be attributed to occupational factors (either conductive or severe unilateral hearing losses, and hearing losses which did not have the high-frequency configuration).

\section{Immittance audiometry}

An immittance audiometry test battery was administered to all the subjects. The battery consisted of tympanometry, static compliance, crossed and uncrossed acoustic reflex testing (at frequencies of $0.5,1$ and $2 \mathrm{kHz}$ ), a reflex decay test (at frequencies of $0.5,1$ and $2 \mathrm{kHz}$ ), and a physical volume test. The main objective in performing immittance audiometry was to obtain information on le- 
sion site by investigating the acoustic reflex findings in the studied groups. The acoustic reflex tests were chosen because of their reliability, availability, and ease of administration. The interacoustics SD30 immittance audiometer underwent electroacoustic calibration prior to the data collection and biological calibration every morning before the subjects were tested.

\section{Data analysis strategies}

A computer program written in Clipper ${ }^{\oplus}$ was used to enter the data into $\mathrm{dBase} I V+{ }^{\circledR}$ files. Extensive checks and rechecks were made for invalid codes or consistency errors. After all the errors were corrected, a clean data file was ready for analysis. The data were analyzed using the statistical analysis system (29). Multiple logistic regression was performed for the estimation of the odds ratios and the testing for interactions.

\section{Results}

\section{Hearing-related issues}

Ninety-three percent of the workers reported no noise exposure to firearms, power tools, amplified music, motorcycles, or tractor driving. The use of hearing protection both on and off the job was assessed in the questionnaire and reported to be low. Only $11 \%$ of the workers exposed to noise above $85 \mathrm{~dB}(\mathrm{~A})$ TWA reported using hearing protectors (ear muffs) during $100 \%$ of the time when noise-exposed. Two of the most common reasons given by the workers for their limited usage of hearing protection were (i) its interference with communication, reported by $70 \%$ of those that reported some use of hearing protection, and (ii) its interference with the execution of their jobs, reported by $46 \%$ of the same subgroup. The issue of noncompliance with the requirement to wear hearing protection has been explored elsewhere (29).

Of the $23 \%$ of the workers who reported tinnitus, $75 \%$ were in the subgroup with the highest noise exposure. Pearson correlation tests indicated a low but significant correlation between tinnitus and alcohol consumption $(\mathrm{r}=0.29, \mathrm{P}<0.001)$, and tinnitus and coffee consumption $(\mathrm{r}=0.18, \mathrm{P}<0.05)$.

\section{Association between hearing status and exposure conditions}

Each audiogram was evaluated for hearing loss. The audiogram was considered to be normal if the thresholds did not exceed $25 \mathrm{~dB}(\mathrm{~A})$ in any tested frequency. If the audiogram revealed a notch in one of the frequencies between 3 and $6 \mathrm{kHz}$, or the thresholds were the poorest in this frequency range, it was classified as high-frequency hearing loss. The prevalence of bilateral high-frequency sensorineural hearing loss found in the study group was $49.2 \%$.
The high-frequency hearing losses were examined using multiple logistic regression for the estimation of the odds ratio and the testing for interactions. For this analysis, conductive and unilateral hearing losses were entered as normal hearing, since they could not be clearly related to the occupational exposures. The bilateral high-frequency hearing losses were examined as a binary outcome variable (normal hearing versus high-frequency hearing loss). The variables considered for inclusion in the model were age, occupational exposure data [including noise dose, noise TWA, exposure indices for the solvent mixture and for each of the solvents (toluene, ethyl acetate, ethanol) and the BEI for toluene], job category, department, tenure, previous occupational exposure to noise or to chemicals, exposure to nonoccupational noise, use of hearing protection, alcohol consumption (volume and duration in years), smoking (in number of cigarettes a day times the number of years of smoking), medical history, medications, and the perception of work conditions and work organization. Some of the variables, such as age, tenure and exposure data, were entered as continuous variables. The interpretation of the estimated coefficient depended on how it was entered into the model and the particular units of the variable. A method was developed for point and interval estimation for an arbitrary change of $x$ units in the covariate (30). The goal in selecting the value for $x$ was choosing the value which offered the clearest indication of how the risk of the outcome being present changed with the variable in question. The interpretation of the estimated coefficient for a continuous variable is similar to that of nominal scaled variables (an estimated log odds ratio). The main difference was that a meaningful change must be defined for the continuous variable (30).

The approach used was stepwise logistic regression. That is, at each step, the variable with the lowest $\mathrm{P}$-value (less than 0.05 ) is added to the model and those with a Pvalue greater than 0.05 are removed from the model. Only the variables that add appreciably to the predictive power of the model remain in it. The only variables that met the significance level criterion for remaining in the model were age, tenure, each of the solvents and noise limit-normalized levels, levels of urinary hippuric acid, and history of repeated ear infections. Table 5 gives the results of the final multiple logistic regression model selected by the stepwise procedure, with the odds ratios for developing hearing loss, calculated for the best ear, and the $95 \%$ confidence intervals. The odds ratio was calculated for each 1-year increase in age. The odds ratio was also estimated for the increase in probability for developing hearing loss with each increase of $1 \mathrm{~g}$ of hippuric acid per gram of creatinine in urine. No significant interactions were noted between the solvents, the solvent mixture and noise, or each individual solvent and noise. 
Table 5. Results of the multiple logistic regression for occupational hearing loss. ( $\mathrm{SE}=$ standard error, $95 \% \mathrm{Cl}=95 \%$ confidence interval, $E \mathrm{I}=$ exposure index, $\mathrm{BEI}=$ biological exposure index)

\begin{tabular}{|c|c|c|c|c|c|c|}
\hline Variable & Beta & SE & $x^{2}$ & P value ${ }^{\hat{a}}$ & OR & $95 \% \mathrm{Cl}$ \\
\hline Intercept ${ }^{b}$ & -3.04 & 1.13 & 7.10 & 0.0077 & - & \\
\hline Age & 0.07 & 0.01 & 13.34 & $0.0003^{*}$ & 1.07 & $1.03-1.11$ \\
\hline Tenure & 0.00 & 0.01 & 0.73 & 0.3932 & 1.00 & $1.00-1.03$ \\
\hline El ethyl acetate & 0.01 & 0.01 & 1.65 & 0.1989 & 1.01 & $1.00-1.03$ \\
\hline El toluene & 0.00 & 0.01 & 0.69 & 0.4037 & 0.99 & $0.98-1.01$ \\
\hline El ethanol & -0.02 & 0.04 & 0.43 & 0.5134 & 0.97 & $0.89-1.06$ \\
\hline Ear infection & -0.33 & 0.66 & 0.25 & 0.6128 & 0.72 & $0.19-2.60$ \\
\hline Noise dose & 0.00 & 0.01 & 0.01 & 0.9436 & 1.00 & $1.00-1.01$ \\
\hline BEl toluene & 0.57 & 0.27 & 4.5 & $0.0338^{*}$ & 1.76 & $1.00-2.98$ \\
\hline
\end{tabular}

asterisks indicate the variables that met the significance level criterion $(P \leq 0.05)$.

b Intercept values represent the proportion of hearing loss when all independent variables equal zero.

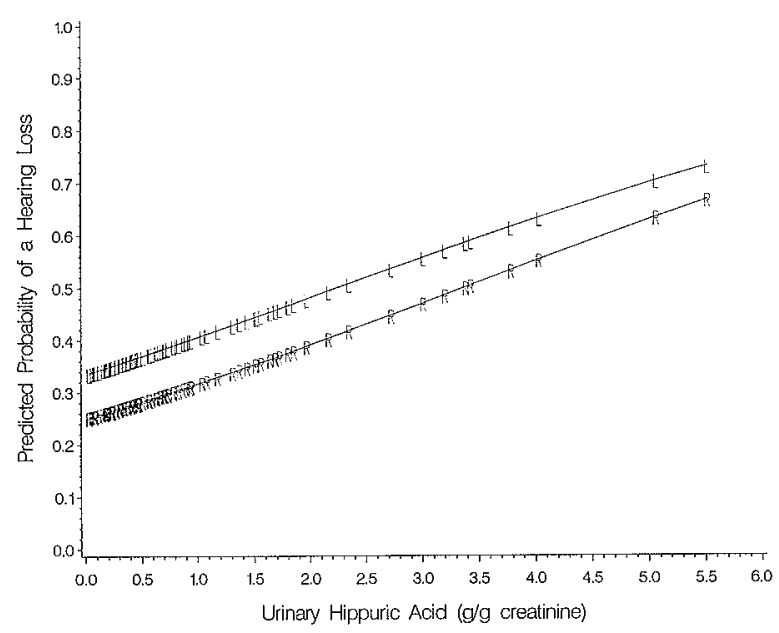

Figure 1. Predicted probability of developing hearing loss, by ear and by the biological determinant of toluene in urine (grams of hippuric acid/ grams of creatinine, $L=$ left ear, $R$ = right ear, each letter in the curve represents a predicted value for one or more persons with a given urinary hippuric acid level).

Table 6. Percentage of cases with acoustic reflex decay, elevated or absent acoustic reflexes, and recruitment by ear, test frequency, and stimulus presentation (ipsilateral or contralateral).

\begin{tabular}{|c|c|c|c|c|}
\hline \multirow[t]{3}{*}{ Frequency } & \multicolumn{4}{|c|}{ Cases of acoustic reflex decay $(\%)$} \\
\hline & \multicolumn{2}{|c|}{ Right ear } & \multicolumn{2}{|c|}{ Left ear } \\
\hline & $\begin{array}{c}\text { Ipsi- } \\
\text { lateral }\end{array}$ & $\begin{array}{l}\text { Contra- } \\
\text { lateral }\end{array}$ & $\begin{array}{c}\text { Ipsi- } \\
\text { lateral }\end{array}$ & $\begin{array}{l}\text { Contra- } \\
\text { lateral }\end{array}$ \\
\hline $\begin{array}{l}500 \mathrm{~Hz} \\
1000 \mathrm{~Hz} \\
2000 \mathrm{~Hz}\end{array}$ & $\begin{array}{r}3.2 \\
31.3\end{array}$ & $\begin{array}{r}7.9 \\
9.5 \\
48.5\end{array}$ & $\begin{array}{r}7.7 \\
35.1\end{array}$ & $\begin{array}{r}6.3 \\
5.6 \\
36.6\end{array}$ \\
\hline \multicolumn{5}{|c|}{ Cases of absence of reflex } \\
\hline $\begin{array}{l}500 \mathrm{~Hz} \\
1000 \mathrm{~Hz} \\
2000 \mathrm{~Hz}\end{array}$ & $\begin{array}{r}19.4 \\
31.5\end{array}$ & $\begin{array}{l}25.8 \\
12.1 \\
15.3\end{array}$ & $\begin{array}{l}20.2 \\
30.9\end{array}$ & $\begin{array}{r}17.7 \\
8.9 \\
15.3\end{array}$ \\
\hline \multicolumn{5}{|c|}{ Cases of elevated reflexes ${ }^{a}$} \\
\hline $\begin{array}{l}500 \mathrm{~Hz} \\
1000 \mathrm{~Hz} \\
2000 \mathrm{~Hz}\end{array}$ & $\begin{array}{l}1.6 \\
2.4\end{array}$ & $\begin{array}{l}20.0 \\
17.7 \\
15\end{array}$ & $\begin{array}{l}2.4 \\
3.2\end{array}$ & $\begin{array}{l}20.2 \\
22.6 \\
13.7\end{array}$ \\
\hline \multicolumn{5}{|c|}{ Cases of recruitmenta } \\
\hline $\begin{array}{l}500 \mathrm{~Hz} \\
1000 \mathrm{~Hz} \\
2000 \mathrm{~Hz}\end{array}$ & $\begin{array}{l}. \\
3.2 \\
1.6\end{array}$ & $\begin{array}{l}3.2 \\
1.6 \\
0.8\end{array}$ & $\begin{array}{l}2.4 \\
1.6\end{array}$ & $\begin{array}{l}0.8 \\
0.8 \\
1.6\end{array}$ \\
\hline
\end{tabular}

a By ear and stimulus presentation.

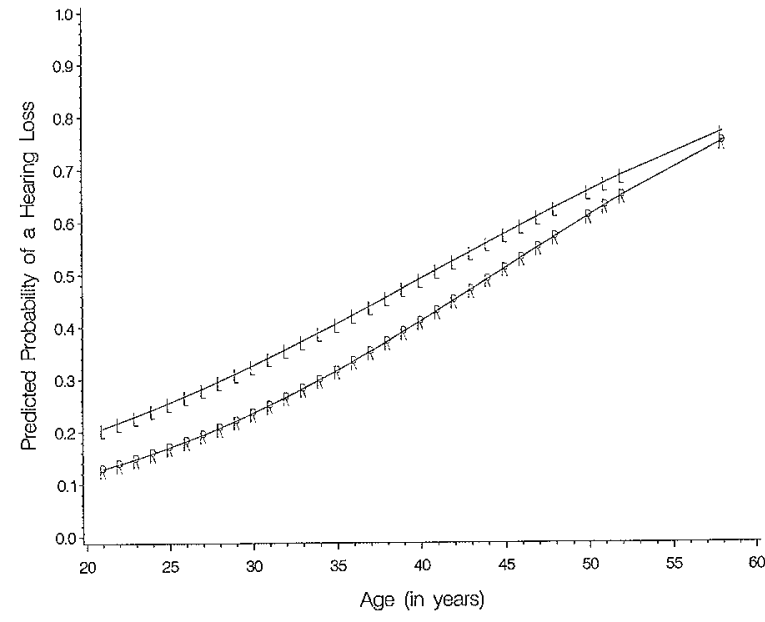

Figure 2. Predicted probability of developing hearing loss, by ear and age. ( $L=$ left ear, $R=$ right ear, each letter in the curve represents a predicted value for one or more persons at a given age).

The predicted probability of the participants to develop hearing loss, based on the levels of urinary hippuric acid is illustrated in figure 1. The probability of hearing loss by increase in age is illustrated in figure 2 .

\section{Acoustic reflex measurements}

The measures analyzed were the absence or elevation of the reflex (in relation to expectation based on normal ears or ears with cochlear hearing losses), the presence of recruitment [observed when the difference between the pure tone and acoustic reflex thresholds was less than $60 \mathrm{~dB}$ (SL)], and the presence of acoustic reflex decay $(50 \%$ reflex decay before $10 \mathrm{~s}$ ). The percentage of cases of the various outcomes is presented in table 6 .

\section{Discussion}

To assess the workers' hearing status, pure-tone audiometry and immittance audiometry were performed. Both 
the noise and solvent exposures were measured. All the subjects were interviewed with regard to medical history, work history, work perception, and solvent and noise exposures.

Information from the sound pressure levels and noise dosimetry indicated that approximately $60 \%$ of the study population was exposed to noise doses considered to be high enough to cause hearing loss. Regarding solvent exposure, measurements performed during this investigation showed that most exposures to toluene and ethyl acetate were within recommended exposure limits. The ethanol exposures never exceeded the recommended exposure limits. In this company, various combinations of solvent and noise exposure were observed.

The prevalence of bilateral high-frequency hearing loss was $49.2 \%$. The high-frequency hearing losses were examined in a multiple logistic regression for the estimation of odds ratios. Age and the biological marker for toluene were the only variables that met the significance level criterion in the final regression model. The increase in the prevalence of high-frequency hearing loss with age has been studied extensively. For a recent review on aging-related hearing loss see Rosenhall \& Pedersen (30). The odds ratio estimates obtained in the present study were 1.07 times greater for each increment of 1 year of age $(95 \%$ CI $1.03-1.11)$ and 1.76 times greater for each increment of $1 \mathrm{~g}$ of hippuric acid per gram of creatinine in urine (95\% CI $1.00-2.98)$.

For the solvents investigated in our study, there is evidence available on the ototoxicity of high concentrations of toluene, both alone or as a component of solvent mixtures $(1,2,7,15,31)$. Animal experiments which evaluated the effects of combined exposures to toluene and ethanol ( 2 of the solvents used in the studied company), revealed that exclusive exposure to ethanol did not affect the auditory system $(32,33)$. In combination with toluene, ethanol exposure has been reported to impair rats' performance further in conditioned avoidance responses (32) and reduce (33) the effect of toluene on auditory sensitivity. The outcomes of these studies are not as contradictory as they may seem, since different exposure parameters and test procedures were used. The test of conditioned avoidance response involves the interpretation of auditory information and motor functions, while the auditory brainstem response is an electrophysiological measurement of auditory sensitivity. Thus the observed interactions may be situated in different sites of the auditory system. For a review of the effects of toluene on the auditory system see Morata et al (34).

The toluene concentration in air was not found to be significantly associated with hearing loss, while the biological determinant of toluene (urinary hippuric acid) was. Measurements of chemicals in air do not reflect the total exposure of the individual. Toluene, for instance, is rapidly absorbed through the skin $\left(14-23 \mathrm{mg} / \mathrm{cm}^{2}\right)(35)$.
Toluene was easily accessible in the studied company, and there is a casual approach to its use. Despite complaints of skin irritation (22\%), it is common to observe workers using solvents to mop floors and clean their hands and machinery (22).

Hippuric acid is a nonspecific urinary metabolite of toluene. It is a common urinary constituent, originating mainly from food (36). Urinary hippuric acid of $2.5 \mathrm{~g} / \mathrm{g}$ creatinine was first recommended by ACGIH in 1984 as one of the biological exposure indices for occupational exposure to toluene at a threshold limit value of $100 \mathrm{ppm}$ $(24,36)$. Currently, ACGIH still lists the $2.5 \mathrm{~g}$ of hippuric acid as the BEI for toluene, but it has also included its BEI in the Notice of Intent to Establish or Change after the TLV of toluene was changed from 100 to $50 \mathrm{ppm}$ in 1993 (24). Field studies conducted during the 1970s and 1980 s indicated that the hippuric acid level correlated well with occupational exposure to toluene at air concentrations of $\geq 100 \mathrm{ppm}$ (37). Now, due to its high background levels in many countries ( 1 to $1.5 \mathrm{~g}$ ), hippuric acid is no longer considered a good biological marker for occupational exposure to toluene below $50 \mathrm{ppm}$, but it is still recommended as an easy-to-analyze biological marker for exposure to toluene when background nonoccupational levels of toluene are low (37). Since low hippuric acid levels were observed for the majority of the studied group, which had no or little occupational exposure to toluene $(52 \%$ with $0.5 \mathrm{~g} / \mathrm{g}$ creatinine of hippuric acid or less; $75 \%$ with $1 \mathrm{~g} / \mathrm{g}$ creatinine or less), this marker provided valuable information on occupational exposure.

The association of the biological determinant of toluene and hearing loss raises serious concerns. At the ACGIH recommended limit level for hippuric acid of $2.5 \mathrm{~g} / \mathrm{g}$ creatinine (which corresponds to $100 \mathrm{ppm}$ in air), the odds ratio for hearing loss estimated in the present study is already 4.4 (odds ratio 1.76 per gram $\cdot 2.5 \mathrm{~g} / \mathrm{g}$ creatinine of hippuric acid $=4.4,95 \%$ CI $2.50-7.45$ ). The ACGIH TLV of $50 \mathrm{ppm}$ is one of the lowest international recommended limits for toluene (23), and, even for this concentration, the estimated odds ratio is greater than 2. The Occupational Safety and Health Administration (OSHA) set a maximum level of 4 times the level recommended by ACGIH (23) (ie, $200 \mathrm{ppm}$ ). The $\mathrm{NIOSH}$ recommends an exposure limit of twice that of ACGIH (23) (ie, $100 \mathrm{ppm}$ ). Each of these exposure limits may be adequate for preventing a series of health outcomes, but none of them seem to be adequate for preventing toluene-induced hearing loss. On the other hand, there is the possibility that peak, nontrivial exposures to solvents may be contributing considerably to the losses. Thus a lowering of limit-normalized levels might not eliminate the risk. More research on solvent-induced hearing loss is needed to address the issue of the adequacy of recommended limits.

Scand J Work Environ Health 1997, vol 23, no 4 
No statistical interactions were noted for the solvents, or between toluene and noise, in causing hearing loss. Since the workers who participated in the study had a relatively short noise exposure time, it is likely that they have not been exposed long enough to allow for the noise effects to be detectable. Noise exposure is not a necessary factor for toluene to produce hearing loss in rats $(7,38,39)$. However, it is certain that noise exposure puts the auditory system in stress (40), so it is plausible to assume that noise exposure might have facilitated the occurrence of the observed toluene-induced hearing losses.

Even though information on the mechanisms underlying the effects of solvents on the auditory system is lacking, the available evidence raises serious concerns regarding workers exposed to combinations of noise and chemical agents. Hitherto, occupational hearing conservation programs have not taken chemical exposures into consideration, whether occupational or nonoccupational. The data from this study and other recent publications indicate that certain chemical exposures should be monitored and controlled as part of the effort to prevent hearing loss. The inclusion of solvent-exposed workers in hearing conservation programs, regardless of their noise exposure, is recommended. Testing the hearing of solvent-exposed workers periodically would allow the early detection of any disorder. Once a disorder is detected, intervention measures could be directed towards controlling the development of the disorders and reducing the exposure to the associated risk factor. Further research is needed to identify the ideal method for testing solventexposed workers on a periodic basis and to determine the ideal interval between tests.

The results of the acoustic reflex decay test suggest that there might be retrocochlear or central auditory pathway involvement in some of the hearing disorders observed. While recruitment (an abnormal abrupt increase in the sensation of loudness measured close to the audiometric threshold) helps to identify the site of a lesion as cochlear, the other outcomes analyzed, such as absence or elevation of acoustic reflexes, are indicators of retrocochlear disorders $(41-43)$. Since the effects of noise are recognized to be cochlear (44), the evidence of retrocochlear sites of hearing loss can help in the differentiation of the effects of noise from the effects of solvents. Although these test results do not conclusively uphold diagnostic statements, they constitute strong evidence about the site of lesion.

In an earlier study conducted with rotogravure printing workers, a group of workers exposed to noise and toluene had a significantly greater $(\mathrm{P}<0.001)$ percentage of cases of reflex decay at every test frequency than the other groups (15). Studies were conducted on auditory and vestibular functions of workers exposed to a mixture of unspecified alcohols, jet fuels, and aromatic solvents
(18-21). The findings of pure-tone audiometry, reflex decay, and speech discrimination testing did not indicate measurable damage due to solvent exposure that was distinguishable from the effects of noise. However, significant abnormalities were found in tests such as distorted speech discrimination and cortical responses, which assessed more central portions of the auditory pathways. This evidence indicated that the ideal procedure for assessing the effects of solvents on hearing required the testing of more central portions of the auditory system, to complement the information provided by pure-tone audiometry.

\section{Concluding remarks}

In this study, occupational exposure to toluene was shown to increase the probability of hearing loss, with an odds ratio of 1.76 for each gram of hippuric acid per gram of creatinine in urine. Biological exposure indices represent the values of determinants which were the most likely to be observed in specimens collected from healthy workers with inhalation exposure to the threshold limit value. In the case of toluene, the ACGIH BEI (which corresponds to the TLV of $100 \mathrm{ppm}$ in air) is $2.5 \mathrm{~g} / \mathrm{g}$ creatinine in urine. Our data indicated that, at this level, the risk for developing hearing loss exceeded 4 . The need for further research on the ototoxicity of industrial chemicals is underscored by the findings of this study. Current recommended exposure limits do not adequately address situations where combined exposures occur, and they do not take into consideration the ototoxicity of industrial chemicals.

\section{Acknowledgments}

This study was financially supported by grant numbers $50.1831 / 91-6$ and 52.0704/94—0 from the Brazilian Conselho Nacional de Desenvolvimento Científico e Tecnológico (CNPq) and by NIOSH.

We would like to express our appreciation to Vera Poco Ramos, from the Pontifical Catholic University of São Paulo, and the company's human resources personnel for their participation in the field study. We thank the workers that agreed to participate in the study for their time, interest, and cooperation.

\section{References}

1. Rebert CS, Sorenson SS, Howd RA, Pryor GT. Toluene induced hearing loss in rats evidenced by the brainstem auditory evoked response. Neurobehav Toxicol Teratol 1983; 5(1):5962. 
2. Pryor GT, Dickinson J, Feeney E, Rebert CS. Transient cognitive deficits and high-frequency hearing loss in weanling rats exposed to toluene. Neurobehav Toxicol Teratol 1983; 5(1): $53-7$.

3. Pryor GT, Rebert CS, Howd RA. Hearing loss in rats caused by inhalation of mixed xylenes and styrene. J Appl Toxicol 1987;7(1):55-61.

4. Nylén P, Hagman M. Function of the auditory and visual systems and peripheral nerve, in rats after long-term combined exposure to $n$-hexane and methylated benzene derivates, II: xylenes. Pharmacol Toxicol 1994;74:124-9.

5. Rebert CS, Schwartz RW, Svendsgaard DJ, Pryor GT, Boyes WK. Combined effects of paired solvents on the rat's auditory system. Toxicology 1995;105:345-54.

6. Lasky RE, Maier MM, Snodgrass EB, Hecox KE, Laughlin NK. The effects of lead on otoacoustic emissions and auditory evoked potentials in monkeys. Neurotoxicol Teratol 1995; 17(6):633-44

7. Johnson AC, Juntunen L, Nylén P, Borg E, Hoglund G. Effect of interaction between noise and toluene on auditory function in the rat. Acta Otolaryngol (Stockh) 1988;105:56-63.

8. Muijser H, Lammers JHCM, Kulig, BM. Synergistic effects of combined exposure to trichloroethylene and noise on hearing in the rat: TNO Nutrition and Food Research InstituteToxicology Division, annual report. Zeist: TNO, 1993-1994. Toxicology 1993-1994:53.

9. Young JS, Upchurch MB, Kaufman MJ, Fechter LD, Carbon monoxide exposure potentiates high-frequency auditory threshold shifts induced by noise. Hear Res 1987;26:37-43.

10. Johnson A-C, Nylén PR. Effects of industrial solvents on hearing. In: Morata TC, Dunn DE, editors. Occupational hearing loss. Philadelphia (PA): Hanley \& Belfus, Inc, 1995, 62340. Occupational medicine: state of the art reviews, vol 10 , no 3 .

11. Bergström B, Nyström B. Development of hearing loss during long term exposure to occupational noise. Scand Audiol 1986; 15:227-34.

12. Muijser H, Hoogendijk EMG, Hooiisma J. The effects of occupational exposure to styrene on high frequency thresholds. Toxicology 1988;49:331-40.

13. Agency for Toxic Substances and Disease Registry (ATSDR)/ Division of Health Studies. National exposure registry-trichloroethylene (TCE) subregistry-baseline technical report 1993. Washington (DC): US Department of Health and Human Services, 1993

14. Jacobsen $P$, Hein $\mathrm{HO}$, Suadicani $P$, Parving A, Gyntelberg F, Mixed solvent exposure and hearing impairment, an epidemiological study of 3284 men: the Copenhagen male study. J Occup Med 1993;43(4):180-4.

15. Morata TC, Dunn DE, Kretschmer LK, Lemasters GK, Keith RW. Effects of occupational exposure to organic solvents and noise on hearing. Scand J Work Environ Health 1993;19: $245-54$

16. Morata TC. Study of the effects of simultaneous exposure to noise and carbon disulfide on worker's hearing. Scand Audiol 1989;18:53-8.

17. Morata TC, Engel T, Durão A, Costa TRS, Krieg E, Dunn DE, et al. Hearing loss from combined exposures among petroleum refinery workers. Scand Audiol. In press.

18. Ödkvist LM, Bergholtz LM, Åhlfeldt $\mathrm{H}$, Andersson B, Edling C, Strand E. Otoneurological and audiological findings in workers exposed to industrial solvents. Acta Otolaryngol 1982;suppl 386:249-51.

19. Ödkvist LM, Arlinger SD, Edling C, Larsby B, Bergholtz LM.
Audiological and vestibulo-oculomotor findings in workers exposed to solvents and jet fuel. Scand Audiol 1987;16: $75-81$.

20. Möller C, Ödkvist LM, Thell J, Larsby B, Hydén D, Bergholtz $\mathrm{LM}$, et al. Otoneurological findings in Psycho-organic syndrome caused by industrial solvent exposure. Acta Otolaryngol 1989;107:5-12.

21. Möller C, Ödkvist L, Larsby B, Tham R, Ledin T, Bergholtz L. Otoneurological findings in workers exposed to styrene. Scand J Work Environ Health 1990;16:189-94

22. Fischer FM, Morata TC, Liber R, Colacioppo S, Fiorini AC, Gozzoli L, et al. Efeitos combinados de estressores ambientais e organizacionais na saúde dos trabalhadores em empresa do setor gráfico [Combined effects of environmental and organizational stressors on the health of workers from the printing industryl. São Paulo: Research Report- Dept. de Saúde Ambiental-Faculdade de Saúde Pública da Universidade de São Paulo, 1996.

23. Eller PM, ed. Manual of analytical methods, 4th ed. Cincinnati $(\mathrm{OH})$ : National Institute for Occupational Safety and Health (NIOSH), 1994. DHHS/NIOSH publication no 94-113.

24. American Conference of Governmental Industrial Hygienists (ACGIH). Threshold limit values and biological exposure indices for 1995-1996. Cincinnati (OH): ACGIH, 1995.

25. Ministério do Trabahho. Secretaria de Segurança-Higiene e Medicina do Trabalho, Brasil. Segurança e Medicina do Trabalho Lei n. 6514 de 22 de dezembro de 1977, Norma Regulamentadoras (NR) aprovadas pela portaria 3214 de 8 de junho de 1978 [Safety and occupational medicine law n. 6514 of December 22, 1977, Regulatory Norms (RN) approved by line 3124 of June 8, 1978]. São Paulo, Ed. Atlas 1996; NR-15 Anexo 11.

26. Carvalho D, Lanchote V, Bonato P, Queiroz RSA, Dreossi S. A new derivatization procedure for the analysis of hippuric acid and m-methyl-hippuric acid by gas chromatography. Int Arch Occup Environ Health 1991;63:33 - 7.

27. American National Standards Institute (ANSI). Maximum permissible ambient noise levels for audiometric test rooms. New York (NY): ANSI, 1991. ANSI S3.1.-1991.

28. International Standardization Organization (ISO). Acoustics - standard reference zero for the calibration of pure tone audiometers. Geneva: ISO, 1991. ISO 389-1964.

29. Hosmer Ir DW, Lemeshow S. Applied logistic regression. New York (NY): John Wiley and Sons, 1989:56-8

30. Rosenhall U, Pedersen KE. Presbycusis and occupational hearing loss. In: Morata TC, Dunn DE, editors. Occupational hearing loss. Philadelphia (PA): Hanley \& Belfus, Inc, 1995:593-607. Occupational medicine: state of the art reviews, vol 10 , no 3 .

31. Nylén P, Hagman M, Johnson A-C. Function of the auditory and visual systems, and of peripheral nerve, in rats after longterm combined exposure to $n$-hexane and methyladed benzene derivatives, I: toluene. Pharmacol Toxicol 1994;74:116-23.

32. Pryor GT, Howd RA, Uyeno ED, Thurber AB. Interactions between toluene and alcohol. Pharmacol Biochem Behav 1985;23(3):401-10.

33. Nylén P, Hagman M, Johnson A-C. Function of the auditory system, the visual system, and peripheral nerve and long-term combined exposure to toluene and ethanol in rats. Pharmacol Toxicol 1995;76:107-11.

34. Morata TC, Nylén PR, Johnson A-C, Dunn DE. Auditory and vestibular functions after single or combined exposure to toluene: a review. Arch Toxicol 1995;69:413-43.

35. Andrews LS, Snyder R. Toxic effects of solvents and vapors. 
In: Klaasen CD, Amdur MO, Doull J, editors. Casarett and Doull's toxicology: the basic science of Poisons, 3rd ed. New York (NY): MacMillan Publishing Company, 1986.

36. Lauwerys RR, Hoet P. Industrial chemical exposure: guidelines for biological monitoring. 2nd edition. Boca Raton (FL): Lewis Publishers, 1993.

37. Chang MJW, Hsu KH, Chen YC, Hsieh LL, Luo, JJ. Biological monitoring of urinary hippuric acid in a Taiwanese semiconductor company: abstracts of the international symposium on biological monitoring in occupational and environmental health; 1996 Sept 11-13, Espoo. Helsinki: Finnish Institute of Occupational Health, 1996.

38. Pryor GT, Howd RA. Toluene induced ototoxicity by subcutaneous administration. Neurobehav Toxicol Teratol 1986;8(1): $103-4$.

39. Sullivan MJ, Rarey KE, Conolly RB. Ototoxicity of toluene in rats. Neurotoxicol Teratol 1989;10:525-30.
40. Henderson D, Hamernik RP. Biologic basis of noise-induced hearing loss. In: Morata TC, Dunn DE, editors. Occupational hearing loss. Philadelphia (PA): Hanley \& Belfus, Inc, 1995:513 - 34. Occupational medicine: state of the art reviews, vol 10 , no 3 .

41. Jerger J, Jerger $S$, Mauldin L. Studies in impedance audiometry, normal and sensorineural ears. Arch Otolaryngol 1972;96: $513-23$.

42. Borg $E$. On the neuronal organization of the acoustic middle ear reflex: a physiological and anatomical study. Brain Res 1973;49:101-23.

43. Northern JL, Gabbard SA, Kinder DL. The acoustic reflex. In: Katz J, editor. Handbook of clinical audiology. 3rd edition. Baltimore (MD): Williams \& Wilkins, 1985.

44. Lindgren $F$, Nilsson $R$, Axelsson $A$. The acoustic reflex threshold in relation to noise-induced hearing loss. Scand Audiol $1983 ; 12 ; 49-55$.

\section{Appendix}

\section{Sections of the interview protocol — University of São Paulo School of Public Health Study of the Effects of Environmental and Organizational Stressors on Workers' Health}

1. Demographic data (including job description).

2. Perception of shift work.

3. Perception of work-related stressors including noise, solvents, physical characteristics of the workplace and ergonomic stress.

4. Job characteristic measures (eg, job demands, decision latitude, control over work, social support and career perspectives).

Received for publication: 10 January 1997
5. General health and well being (eg, physical and psychological health, satisfaction)

6. Medical history.

7. Descriptions of previous and nonoccupational exposures to noise or solvents.

8. Results of audiological tests.

9. Results of noise and solvent measurements. 